\title{
Self-image and suicidal and violent behaviours of adolescent girls
}

\section{BACKGROUND}

An increase in self-destructive and aggressive behaviours in adolescents has been observed in recent years. The present study focused on self-perception of adolescent girls who show different types of extreme destructive behaviours (suicidal or violent). The main aim of the study was to identify personality predictors of suicidal and violent behaviour in adolescent girls.

\section{PARTICIPANTS AND PROCEDURE}

The study involved 163 female participants aged 13-17 years, including 44 suicide attempters (without extreme aggressive behaviour towards others), 46 girls using violence against others (without extreme self-destructive behaviour) and 77 girls exhibiting no destructive behaviour. The following research methods were applied: the Adjective Checklist (ACL) (versions "What am I like?" and "What would I like to be?"), and the Sentence Completion Test.

\section{RESULTS}

The girls showing extreme destructive behaviour, particularly self-destructive behaviour, were found to have a more negative self-image, a lower level of consistency of the self-image, lower self-esteem and a higher level of inner conflict than the control group. Stepwise discriminant analysis was used to determine predictors of extreme self-destructive or aggressive behaviours. Escalated inner conflicts within the attitude towards oneself appear to be the most important predictor of suicidal behaviour in adolescent girls, whereas self-perception based on strength seems to be the most significant predictor of violent behaviour in adolescent girls.

\section{CONCLUSIONS}

The research showed that destructive behaviour among adolescents is a multidimensional phenomenon. The statistical model presented in the study has been proved to have a high value. The results can help in successful prevention and therapy of destructive behaviours in adolescents.

\section{KEY WORDS}

self-image; suicide attempt; self-destructive behaviour; interpersonal violence; aggressive behaviour

ORganization - Department of Psychology, School of Health Sciences in Katowice, Medical University of Silesia,

Katowice, Poland

authors' Contributions - A: Study design - B: Data collection - C: Statistical analysis - D: Data interpretation .

E: Manuscript preparation · F: Literature search · G: Funds collection

Corresponding Author - Katarzyna Sitnik-Warchulska, Ph.D., Department of Psychology, School of Health Sciences

in Katowice, Medical University of Silesia, 12 Medyków Str., 40-752 Katowice, Poland, e-mail: k.sitnikwarchulska@ gmail.com

TO CITE THIS ARTICLE - Sitnik-Warchulska, K. (2016). Self-image and suicidal and violent behaviours of adolescent girls.

Health Psychology Report, 4(4), 303-314. doi: 10.5114/hpr.2016.59911

RECEIVED 06.12.2015 - REVIEWED 21.01.2016 · ACCEPTED 25.04.2016 · PUBLISHED 20.05.2016 


\section{BACKGROUND}

An increase in extremely self-destructive and aggressive behaviours among youth has been observed in the past few years. According to the data provided by the World Health Organization (2014), suicide, which is the ultimate form of self-destruction, is currently the second leading cause of death among people aged 15-29 years. In turn, the extreme form of aggression which is interpersonal violence is the third leading
Katarzyna Sitnik-Warchulska cause of death among people aged 10-29 years (Jakab, 2010). Recent Polish studies conducted by Pawłowska, Potembska, Zygo, and Olajossa (2015) indicate that self-injurious behaviour occurs in as many as $24.91 \%$ of adolescents aged 13-19 years, whereas as many as $47.65 \%$ engage in suicidal ideation. Meanwhile, according to a report on the WHO's research carried out as part of the Health Behaviour in School-aged Children study (HBSC), $24.00 \%$ of 13-year-old students interviewed in Poland had taken part in fights at least three times over the last twelve months. At the same time, $23.00 \%$ of teenagers admitted to using peer violence in schools in the last few months (Currie et al., 2012).

The rising concern in clinical circles is caused mainly by the observed increase in suicidal and violent behaviours among adolescent girls. Suicide attempts are 2 to 3 times more common among girls than boys. Self-injurious behaviour and suicidal ideation are more frequent and persist for a longer period of time in adolescent girls (Cash \& Bridge, 2009; Law \& Shek, 2015), who are often violence perpetrators. Observations conducted by Haight, Marshall, Hans, Black, and Sheridan (2010) indicate that the degree of involvement in direct physical aggression in girls is at least as high as in boys. The participation of adolescent girls in violent crimes punished judicially has been growing rapidly, as well (Biel, 2009).

Moreover, suicidal or violent behaviours of adolescent girls are rarely once in a lifetime experiences. In contemporary medical classifications descriptions of the diagnostic syndromes are connected with repeated suicide attempts (e.g., suicidal behaviour disorder) or a variety of aggressive behaviours (e.g., conduct disorder) (American Psychiatric Association, 2013). Suicide attempts in adolescents may be one of the manifestations of borderline personality disorder (Bleiberg, 1994; Zelkowitz et al., 2004) or the self-critical dysphoric style (Westen \& Chang, 2000). However, impulsive, violent behaviours of young people are understood as a symptom of narcissistic personality or oppositional dysphoric personality style (Westen \& Chang, 2000).

A review of the clinical reports, usually dealing with the phenomena of violence and suicide in adolescents separately, suggests a reflection on the similarity of risk factors for these behaviours and partial similarity of their clinical pictures. Risk factors for suicidal be- haviour during adolescence mainly include depressed mood, mental disorders, substance abuse, intrapsychic problems (i.e., a negative self-image, issues related to emotional control, anxiety, impulsivity, the presence of borderline personality traits, the presence of antisocial characteristics, the presence of the characteristics of narcissism), social isolation, loneliness, traumatic experiences involving, e.g., violence, sexual abuse, loss of significant others, as well as conflicted and dysfunctional family relationships, illness in the family, low economic status of the family, the family and social transmission regarding destruction (Adrian, Miller, McCauley, \& Vander Stoep, 2016; Brausch \& Gutierrez, 2010; King, Kerr, Passarelli, Foster, \& Merchant, 2010; Kuhlberg, Peña, \& Zayas, 2010; Miller, Rathus, \& Linehan, 2007; Pilecka, 2005; Steele \& Doey, 2007; Woźniak, Talarowska, Orzechowska, Florkowski, \& Galecki, 2013). The indicated factors increase the risk of violent behaviour in adolescents (Arim, Dahinten, Marshall, \& Shapka, 2011; Crapanzo, Frick, \& Terranova, 2010; Herba, Tranah, Rubia, \& Yule, 2006; Manseau, Fernet, Hébert, Collin-Vézina, \& Blais, 2008; Pajer, Leininger, \& Gardner, 2010; Rulison, Gest, Loken, \& Welsh, 2010; Undheim \& Sound, 2010). Studies conducted by Vermeiren et al. (2003) indicate that in both adolescents with self-destructive behaviour and teenagers with aggressive behaviour higher rates of depressiveness, somatisation, aggressiveness (explicit and implicit), propensity to engage in risk-taking behaviour and more negative beliefs concerning their future can be observed in comparison to adolescents who do not exhibit destructive behaviour. Hence, the question of what ultimately prompts teenage females to self-destruction rather than aggression and vice versa remains open to further research.

In this respect, the role of the Self may prove significant. The Self is considered the key regulator of behaviour and the core of the emerging adolescent personality. According to Nuttin's concept (1968), the Self is an entity consisting of both a self-image and a mental representation of the world. Self-image is examined mainly in the context of structure, self-esteem, consistency between the image of the real and the ideal self-image, the level of inner conflict and self-concept. Positive self-concept is stated to be a protective factor against different behavioural disorders (Ybrandt, 2008), whereas research observations indicate negative self-representation and negative self-esteem to be related to the occurrence of, inter alia, aggressive, criminal and self-destructive (including suicidal) behaviours in adolescent teenagers (Donellan, Trzesniewski, Robins, Moffitt, \& Caspi, 2005; Kubacka-Jasiecka, 2006; Moretti, Holland, \& McKay, 2001; Zhang, Norvilitis, \& Ingersoll, 2007; Ybrandt, 2008).

The relation between self-destructive, often depressive functioning and a negative self-image seems to be especially characteristic of girls in the middle phase of adolescence (Laukkanen, Honkalampi, Hin- 
tikka, Hintikka, \& Lehtonen, 2005; Ybrandt, 2008). At the same time, researchers have reported clear desires of independence, activity and fulfilment in this group of respondents (Makara-Studzińska, 2001; Pilecka, 2005). In the case of girls who display aggressive behaviours, studies indicate these behaviours to be related to a negative self-image, yet apparently high self-esteem (Ang \& Yusof, 2005; Collin-Vézina, Hébert, Manseau, Blais, \& Fernet, 2006). According to observations carried out by Ang and Yusof (2005), these declarations might have a more wishful character and conceal the real deficiency in the self-image.

Repetitive violent behaviour can therefore be understood as an expression of the struggle to maintain a sense of values, which is de facto very unstable.

Therefore, we can generally determine a negative self-image in both girls with suicidal behaviours and girls with violent behaviours. Nevertheless, the weight of the factors that make up this image in both cases may be different and specific for a given type of destructive behaviour. Distinguishing the most significant factors seems crucial for predicting suicidal or violent behaviour in adolescents.

\section{RESEARCH OBJECTIVES}

The present research focuses on the self-image of contemporary girls who do or do not engage in different extreme destructive behaviours (self-destructive and aggressive). They constitute a part of the author's long-term research explorations concerning different aspects of the Self and their relation to destructive behaviour in adolescence. Self-image was treated in the present research as a multidimensional constituent of the Self, which was acknowledged as the main regulator in adolescence. It was assumed that a negative self-image is associated with both self-destructive and aggressive behaviours. It was also hypothesised that the subjects are differentiated not so much by the type of features constituting the self-image as their structure. In terms of self-image the following constituents were examined: 1) the structure of self-image, 2) the level of self-esteem, 3) the level of consistency of self-image and 4) the level of inner conflict (integration/disintegration). The main objective of the present research was to determine the personality factors which are predictors of suicidal or violent behaviour in adolescent girls.

\section{PARTICIPANTS AND PROCEDURE}

\section{PARTICIPANTS}

One hundred and sixty-three girls aged 13-17 years were surveyed in the course of the research, including 44 suicide attempters (SG group), 46 individuals using violence towards others (AG group) and 73 individuals who do not exhibit destructive behaviour (CG group).

The criteria for allocation of participants to the group which displays extreme self-destructive behaviour (SG) were:

- a medical report on a suicide attempt together with a diagnosis consistent with the ICD-10 classification,

- psychophysical condition allowing for conduction of examinations,

- subjection to initial phase of diagnosis and initial rehabilitation process evinced by relative emotional stability,

- condition/time before initiating the regular psychotherapeutic process,

- lack of aggressive behaviour in the life history.

The criteria of allocation to the group which displays extreme aggressive behaviours (AG) were:

- the presence of spontaneous violent behaviour that meets the criteria of conduct disorder F91 in the ICD-10 classification (which requires occurrence of a repetitive and strengthened pattern of behaviour characterised by violation of the basic rights of other people, occurrence of at least one of the following behaviours: frequent initiation of physical clashes, a crime requiring confrontation with a victim (assault), bullying, use of a weapon which might cause severe injuries to a person's body, physical cruelty towards others, and at least six-month duration of symptoms of the mentioned aggressive behaviours),

- the presence of social and legal consequences related to the behaviour in the form of: at least three instances of intervention of the school/the police and/ or probation and/or a cases of demoralisation and/ or referral to therapy and resocialization (educational care facility; rehabilitation medical facility),

- condition/time before launching the regular psychotherapeutic and rehabilitation processes,

- no record of self-destructive behaviours in the life history.

The group of subjects did not include individuals suspected of or having been diagnosed with psychiatric disorders (i.e., psychosis, autism, impairment, addiction in the form of toxicomania and alcoholism), neurological disorders, somatic disorders connected with serious health complications, or murderers. Additional selection criteria for all participants were age between 13 and 17 years and analogical motivation for the examination process. All the subjects declared openness and willingness to take part in the research.

\section{PROCEDURE}

The present research involved patients of child and adolescent psychiatric facilities, child and adolescent
Self-image and destructive behaviour of adolescent girls 
Katarzyna Sitnik-Warchulska mental health clinics, rehabilitation and medical facilities, as well as foster children of educational care facilities and secondary school students from Silesian Voivodeship (age $M=15.26, S D=0.92$ ). The study was individual, anonymous and voluntary, conducted in accordance with ethical standards for scientific research. The participation was preceded with written consent provided by the subjects and all their legal guardians.

All the subjects who met the mentioned criteria and were willing to take part in the research were informed about the purpose of the study and the course of the examination. The research process included four successive meetings as distinguished individual stages, which took place over several days.

The following methods were used in the research: - The Adjective Check List (ACL) by Gough and Heilbrun (1983) in the Polish adaptation (Martowska, 2012). The questionnaire was used in the research twice: in the version "What am I like?" (the real image) and in the version "What would I like to be?" (the ideal image). The Adjective Check List is based on choosing a feature from a list of 300 adjectives that are part of 37 scales used for diagnosing self-image in terms of its structure, the level of self-esteem and consistency. The obtained quantitative results based on a factor analysis carried out by Polish researchers (Juros \& Oleś, 1993) can be grouped into 6 factors: Potency, Self-confidence, Socialisation, Self-control, Friendliness and Individuality. The value of the reliability coefficient Cronbach's $\alpha$ estimated for the sample of Polish women was .72. A considerable convergence of factorial structures of the Polish and American versions of the test can be seen as confirmation of its accuracy (Juros \& Oleś, 1993).

- The Sentence Completion Test by Sacks and Levy (1950) in the Polish translation of Choynowski. It is a popular structured projection method that involves completing 60 proposed sentences with one's own associations. This device is used in order to determine the severity of intrapsychic conflicts and, therefore, the level of inner integration/disintegration (in the Self). The level of conflict can be assessed with reference to four areas: attitude towards oneself, family, opposite sex and interpersonal relationships. The impartiality of the test is achieved by means of a three-stage estimation scale (assessment of the level of conflict in the categories: strong conflict requiring therapeutic intervention - 2 , moderate conflict -1 , absence of conflict -0 ). In the present paper focus was placed on descriptive and quantitative analyses of the area related to the attitude towards oneself.

The statistical package STATISTICA was used for developing test results. The analysis of variance and post-hoc Tukey's HSD were carried out. Discriminant analysis was used in order to identify the constella- tion of variables characterising a given group and predictors of future suicidal or violent behaviour.

\section{RESULTS}

\section{STRUCTURE OF SELF-IMAGE}

The evaluation of the structure of self-image is based on the analysis of 6 factors specified in the Adjective Check List:

- Potency (determined by the following scales: Achievement - Ach, Endurance - End, Order - Ord, Leadership - Mls, Adult - A, Adapted child - Ac),

- Self-confidence (determined by the following scales: Domination - Dom, Exhibition - Exh, Aggression Agg, Abasement - Aba, Deference - Def, Free child $-\mathrm{Fc}$ ),

- Socialisation (determined by the following scales: Nurturance - Nur, Affiliation - Aff, Critical parent - Cp, Nurturing parent - Np, Low originality - Low intelligence A-3),

- Self-control (determined by the following scales: the total number of adjectives checked - NoCkd, Communality - Com, Personal adjustment - P-Adj, Creative personality scale - Cps, Leadership - Mls, High originality - Low intelligence A-1),

- Friendliness (determined by the following scales: Nurturance - Nur, Heterosexuality - Het, Succorance - Suc, Abasement - Aba, Feminine attributes scale - Fem),

- Individuality (determined by the following scales: Communality - Com, Intraception - Int, Change Cha, Creative personality scale - Cps, High originality - High intelligence A-2).

The characteristics of the listed factors are presented in Table 1.

The results of the overall analysis of variance and Tukey's post-hoc tests for unequal sample sizes indicated lack of differences between the suicide attempters and the subjects using interpersonal violence in terms of factors such as Self-control, Friendliness and Individuality (Table 2). At the same time, the conducted analyses suggested that the participants displaying destructive behaviour scored less in these factors than those who did not exhibit this type of behaviour (significant difference between SG group and CG group, trend between AG group and $\mathrm{CG}$ group). Hence, it can be concluded that the subjects who exhibit extremely different destructive behaviours display clear difficulties in terms of endurance, organising and planning skills, personal adjustment and creativity (understood as sensitivity and openness to new interests, willingness to expand one's horizons). They are characterised by a strong desire for independence, strong focus on oneself, impulsiveness, instability and tendency to distrust, distance and interpersonal anxiety. The suicide attempt- 


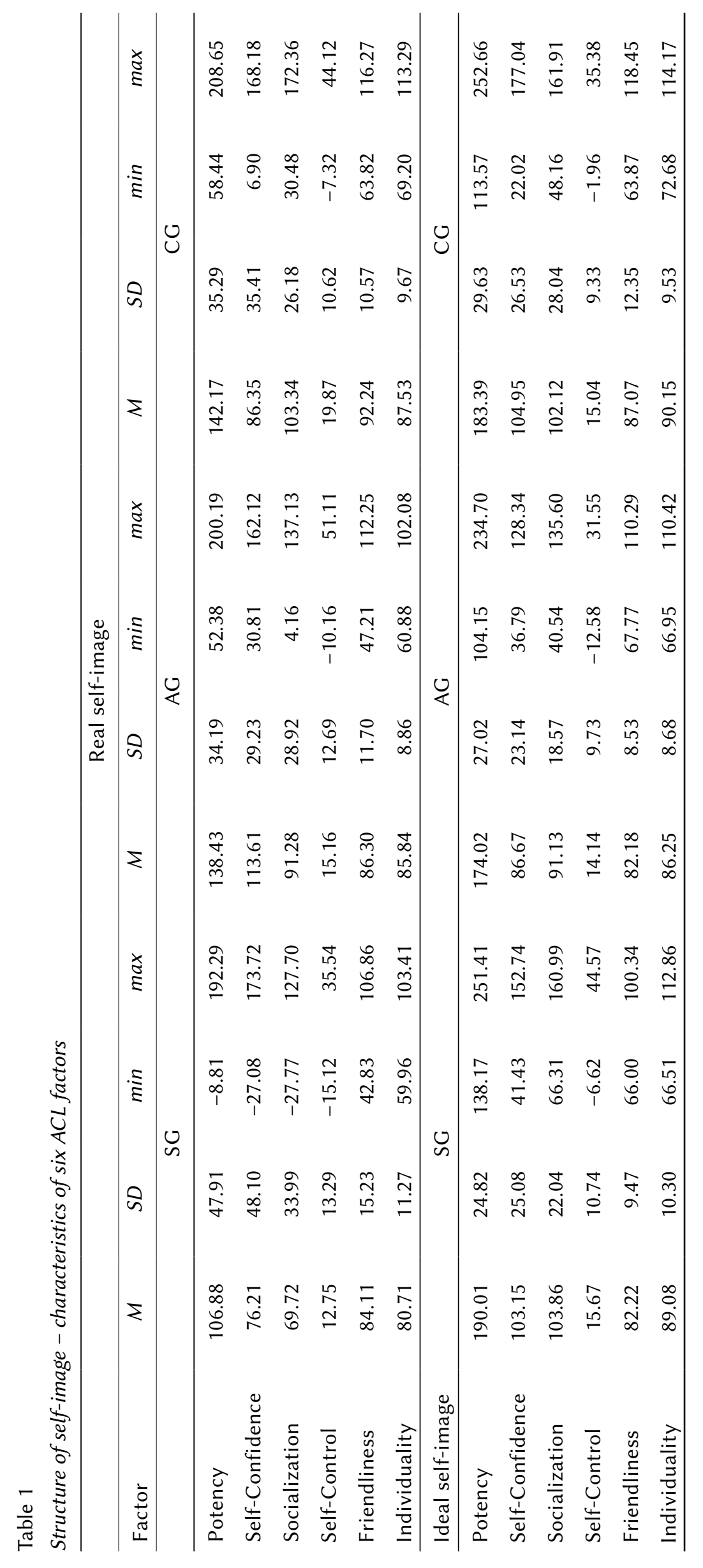

Self-image and destructive

behaviour of adolescent girls 
Katarzyna Sitnik-Warchulska ers exhibited the highest concentration of difficulties in these fields (Table 2). A similar trend especially in terms of distrust and social distance (Friendliness) was observed among the subjects who use interpersonal aggression (AG). This trend proved to coincide with a lower concentration of dependency attitudes in the subjects displaying extreme aggressive behaviour in comparison to those engaging in extreme self-destructive behaviour.

Of all the participants, the individuals who use interpersonal violence (AG) proved to have the strongest desires for leadership, focusing attention on themselves and controlling others, latitude or impetuosity in expressing themselves, as well as the highest level of impatience, difficulty with controlling their behaviour and tendency to display aggression understood in terms of reckoning with others (Self-Confidence: SG-AG $p<.001, \mathrm{AG}-\mathrm{CG} p=.004$ ).

In comparison to the suicide attempters (SG), the subjects displaying extreme aggressive behaviours revealed higher Potency and Socialisation levels (Potency: SG-AG $p<.001$, Socialisation: SG-AG $p=.003)$. This is connected mainly with the fact that the girls who use interpersonal violence show an increased need for achievements, greater ability to achieve specified goals, clearer efforts in pursuing power and success, better organisation and planning skills and, at the same time, exhibit a lower-level distance in interpersonal relations. The highest ratios in this respect were achieved by the control group CG (trend between CG group and AG group, significant difference between $C G$ group and SG group) (Table 2). On the other hand, the lowest ratios for Potency and Socialisation were apparently obtained by the subjects from the group exhibiting extreme self-destructive behaviour (Potency: SGCG $p<.001$, Socialisation: SG-CG $p<.001)$. Their real image is characterised by originality of thinking and, at the same time, the strongest criticism and the greatest distance in interpersonal relations, the strongest deference, and very poorly developed skills related to managing people and gaining power and success (Table 2).

The factors of Self-confidence, Potency and Socialisation proved to significantly differentiate the ideal image of the study participants. Detailed analyses using Tukey's post-hoc tests for unequal sample sizes showed that the subjects using interpersonal violence (AG) wish to present much lower Self-confidence than other participants of the study (Table 3). This indicates that they would like to be much less dominant, impetuous, expressive and independent (in terms of interpersonal relations) than the subjects who do not exhibit destructive behaviour (CG) and the subjects representing extreme self-destructive behaviours (SG). In contrast to the subjects who use interpersonal violence, the individuals from the last group mentioned expect themselves to be more Socialised and have higher Emotional Potency (Socialisation: SG-AG $p=.046$, Potency: SG-AG $p=.026$ ). In terms of the other factors (Self-Control, Friendliness, Individuality), no differences between the surveyed girls were observed. As indicated by the detailed analysis of the results of scales that determine these factors, all the participants turned out to expect from themselves more orderliness, better organisation and planning of their actions, stability and trust in themselves and in others within the limits akin to the social norm (average results, lack of significant differences) (Table 3).

\section{LEVEL OF SELF-ESTEEM}

The level of self-esteem in the study participants (SA) was estimated on the basis of a factor constituting the quotient of the scores obtained by them in scales Fav (quantity of positive adjectives chosen) and NoCkd (the overall quantity of adjectives chosen) of the ACL Test. Detailed characteristics of the obtained indicators of self-esteem in specific groups of respondents are provided in Table 4.

Table 2

Significance of differences in ACL factors in real self-image of examined girls. Results of the analysis of variance (ANOVA) and Tukey's post-hoc tests for unequal sample sizes

\begin{tabular}{lccccc}
\hline & \multicolumn{2}{c}{ ANOVA } & \multicolumn{3}{c}{$p$ Tukey's HSD } \\
\cline { 2 - 6 } & $F(2,137)$ & $p$ & SG-AG & AG-CG & SG-CG \\
\hline Potency & 10.83 & $<.001$ & $<.001$ & .904 & $<.001$ \\
Self-Confidence & 10.57 & $<.001$ & $<.001$ & .004 & .456 \\
Socialization & 15.76 & $<.001$ & .003 & .158 & .001 \\
Self-Control & 4.56 & .012 & .644 & .185 & .022 \\
Friendliness & 5.84 & .004 & .707 & .081 & .009 \\
Individuality & 5.81 & .004 & .055 & .727 & .006 \\
\hline
\end{tabular}

Note. SG - group of girls with extreme self-destructive behaviours (suicide attempts), AG - group of girls with extreme aggressive behaviours (interpersonal violence), CG - control group (girls without destructive behaviour) 
Table 3

Significance of differences in ACL factors in ideal self-image of examined girls. Results of the analysis of variance (ANOVA) and Tukey's post-hoc tests for unequal sample sizes

\begin{tabular}{lccccc}
\hline & \multicolumn{2}{c}{ ANOVA } & \multicolumn{3}{c}{$p$ Tukey's HSD } \\
\cline { 2 - 6 } & $F(2,137)$ & $p$ & SG-AG & AG-CG & SG-CG \\
\hline Potency & 3.40 & .036 & .026 & .282 & .530 \\
Self-Confidence & 7.00 & .001 & .010 & .003 & .945 \\
Socialization & 3.45 & .032 & .046 & .101 & .944 \\
Self-Control & 0.25 & .782 & .765 & .097 & .955 \\
Friendliness & 3.63 & .029 & 1.000 & .159 & .101 \\
Individuality & 2.05 & .132 & .378 & .870
\end{tabular}

Note. SG - group of girls with extreme self-destructive behaviours (suicide attempts), AG - group of girls with extreme aggressive behaviours (interpersonal violence), CG - control group (girls without destructive behaviour)

The results of Tukey's post-hoc tests for unequal sample sizes (Table 5) demonstrated the lowest level of self-esteem among suicide attempters (SG-AG $p=.027$, SG-CG $p<.001)$. A slight reduction in the current self-esteem on the basis of the trend was also observed in the group of subjects using interpersonal violence (AG-CG $p=.538$ ). The desired level of self-esteem (the ideal image) proved not to differentiate the surveyed girls (Table 5).

\section{CONSISTENCY OF SELF-IMAGE}

In order to assess the level of the consistency of self-image, the D distance ratio based on Cronbach's and Gleser's ratios was used (Wolińska \& Drwal, 1995), which constitutes a measurement of similarity/discrepancy of the profiles of the real image and the ideal image in the ACL. Means and standard deviations of the consistency of self-image are presented in Table 6.

The analysis demonstrated that the least consistent is the self-image of the suicide attempters (GSGA $p=.002$, GS-GC $p<.001$ ). On the basis of the trend it can also be concluded that there are some dif- ficulties in terms of consistency of the self-image of the subjects who use interpersonal violence (Table 7).

\section{LEVEL OF INNER CONFLICT}

The analysis of the Attitude Towards Oneself in the Sentence Completion Test allowed the level of inner conflict to be estimated (Table 8).

Tukey's post-hoc tests for unequal sample sizes demonstrated that the subjects who displayed extremely different destructive behaviours are characterised by a higher level and frequency of inner conflict intensity in comparison to the subjects who exhibit no destructive behaviour. The highest level of inner conflict was found in the suicide attempters (SG-CG $p<.001$; SG-AG $p<.001$ ). The inner conflict ratios proved significantly higher also among the girls who display extreme aggressive behaviours (AG-CG $p<.001)$. Meanwhile, a trend was observed indicating a moderate level of tension and anxiety, as well as a certain ability to effectively adapt psychosocially.

A detailed descriptive analysis of these data indicated mainly a significant intensity of the feeling of guilt

Table 4

Level of self-esteem in study participants (SA)

\begin{tabular}{lccccc}
\hline & & $M$ & $S D$ & $\min$ & $\max$ \\
\hline \multirow{2}{*}{ Self-esteem SG } & RS & 0.31 & 0.13 & 0.05 & 0.55 \\
Self-esteem AG & IS & 0.52 & 0.10 & 0.35 & 0.72 \\
& RS & 0.39 & 0.10 & 0.14 & 0.60 \\
Self-esteem CG & IS & 0.48 & 0.14 & 0.07 & 0.74 \\
& RS & 0.43 & 0.10 & 0.23 & 0.65 \\
\hline
\end{tabular}

Note. SG - group of girls with extreme self-destructive behaviours (suicide attempts), AG - group of girls with extreme aggressive behaviours (interpersonal violence), CG - control group (girls without destructive behaviour), RS - real self-image, IS - ideal self-image

Self-image and destructive behaviour of adolescent girls 
Table 5

Significance of differences in self-esteem of examined girls. Results of Tukey's post-hoc tests for unequal sample sizes

\begin{tabular}{|c|c|c|c|c|c|c|}
\hline & \multicolumn{6}{|c|}{ p Tukey's HSD } \\
\hline & SG RS & SG IS & AG RS & AG IS & CG RS & CG IS \\
\hline SG RS & & $<.001$ & .027 & & $<.001$ & \\
\hline SG IS & $<.001$ & & & .667 & & .917 \\
\hline AG RS & .027 & & & .001 & .538 & \\
\hline AG IS & & .667 & .001 & & & .996 \\
\hline CG RS & $<.001$ & & .538 & & & .015 \\
\hline CG IS & & .917 & & .996 & .015 & \\
\hline
\end{tabular}

Note. SG - group of girls with extreme self-destructive behaviours (suicide attempts), AG - group of girls with extreme aggressive behaviours (interpersonal violence), CG - control group (girls without destructive behaviour), RS - real self-image, IS - ideal self-image

Table 6

Consistency of self-image

\begin{tabular}{lllll}
\hline & $M$ & $S D$ & $\min$ & $\max$ \\
\hline Consistency of self-image SG & 18.20 & 7.64 & 6.33 & 40.09 \\
Consistency of self-image AG & 13.50 & 5.33 & 0.00 & 27.17 \\
Consistency of self-image CG & 11.94 & 5.47 & 0.00 & 28.92 \\
\hline
\end{tabular}

Note. SG - group of girls with extreme self-destructive behaviours (suicide attempts), AG - group of girls with extreme aggressive behaviours (interpersonal violence), CG - control group (girls without destructive behaviour)

Table 7

Significance of differences in consistency of self-image of examined girls. Results of Tukey's post-hoc tests for unequal sample sizes

\begin{tabular}{lccc}
\hline & \multicolumn{3}{c}{$p$ Tukey's HSD } \\
\cline { 2 - 4 } & Consistency SG & Consistency AG & Consistency CG \\
\hline Consistency SG & .002 & $<.001$ \\
Consistency AG & .002 & .489 \\
Consistency CG & $<.001$ & .489 & \\
\hline
\end{tabular}

Note. SG - group of girls with extreme self-destructive behaviours (suicide attempts), AG - group of girls with extreme aggressive behaviours (interpersonal violence), CG - control group (girls without destructive behaviour)

Table 8

Characteristics of the attitude towards oneself

\begin{tabular}{lcccc}
\hline & $M$ & $S D$ & $\min$ & $\max$ \\
\hline SG & 61.46 & 19.49 & 25.00 & 100.00 \\
AG & 36.88 & 12.64 & 16.67 & 66.67 \\
CG & 13.47 & 11.69 & 0.00 & 58.33 \\
\hline
\end{tabular}

Note. SG - group of girls with extreme self-destructive behaviours (suicide attempts), AG - group of girls with extreme aggressive behaviours (interpersonal violence), CG - control group (girls without destructive behaviour), SG - group of girls with extreme self-destructive behaviours (suicide attempts), AG - group of girls with extreme aggressive behaviours (interpersonal violence), CG - control group (girls without destructive behaviour) 
(SG: high scores $80.00 \%$, elevated scores $17.50 \%$; AG: high scores $33.00 \%$, elevated scores $53.00 \%$ ), as well as fears and concerns among the subjects who displayed extreme destructive behaviour (SG: high scores $65.00 \%$, elevated scores $20.00 \%$; AG: high scores $7.50 \%$, elevated scores $60.00 \%$ ). The following answers proved to be dominant among the participants exhibiting extreme self-destructive behaviours (SG): feeling guilty because of the suicide attempt and family difficulties, a negative attitude to one's talents, fear of loneliness, rejection, longing for intimacy with the family and realisation of one's own ambitions, and a negative attitude towards the past and the future. In turn, the following statements proved to be dominant among the girls using interpersonal violence (AG): feeling guilty due to one's own behaviour and family difficulties, fear of loneliness, weakness and losing acceptance, need for intimate relations with peers and moderate intensity of conflicts towards the past and the future.

\section{DISCRIMINANT ANALYSIS}

In the context of the overall research analyses the results concerning self-image were included in the discriminant function analysis. This analysis served for differentiating variables which are the best predictors of suicidal behaviour or violent behaviour in the group of girls in the middle phase of adolescence. Of the variables related to self-image, Potency factor (the ACL test) and inner conflict (the Sentence Completion Test) proved to be predictors of destructive behaviours. The most important predictor of suicidal behaviour turned out to be the high level of inner conflict (standardised coefficient of the discriminant function $\beta=.78$ ). In this regard, the subjects who use interpersonal violence were placed between the control group and the group displaying extreme self-destructive behaviours. In reference to self-image, the most important predictor of extremely destructive behaviours proved to be the self-image in the category of Potency (standardised coefficient of the discriminant function $\beta=.50)$. The constructed model proved highly accurate $(88.80 \%$ correct classifications; $83.20 \%$ correctly classified cross-validated observations).

\section{DISCUSSION}

The present research confirmed the hypothesis of the existence of a generally negative self-image among the girls exhibiting extreme destructive behaviour. It can be concluded that they present a more negative structure of self-image in general, greater issues related to self-esteem, a lower level of consistency of the self-image and a higher level of conflict than the girls who do not display destructive behaviour. In reference to those girls we can determine discomfort, slight smugness, inner conflict, intensified emotional dysregulation, exceptionally low endurance, impulsivity, difficulties with orderliness and poor organisational skills, distance and distrust, problems with adapting and, at the same time, a strong desire for independence and being different than one is. Similar observations were made by Vermeiren et al. (2003) and Vivona et al. (1995), leading to the conclusion that extreme destructive behaviours are based on qualities such as aggression, tendency to cross boundaries, instability or a kind of emotional immaturity.

However, comparative analyses conducted for the purpose of the present study revealed a noticeable difference in the manner of shaping a destructive pattern among the girls who exhibited extremely self-destructive and aggressive (towards others) behaviours. The suicide attempters were found mainly to represent inner conflict, weakness and guilt. They emerged as participants with the lowest scores in self-esteem and self-image consistency. It may also be concluded that their characteristic coping mechanism is avoidance based on anxiety and fear of loneliness, loss and lack of attention. On the other hand, the subjects who use interpersonal violence depicted themselves mainly in the categories of power, self-sufficiency, independence from surroundings, freedom and ease of change. Simultaneously, they signalised the inner, conflicted need for being important, happy and successful - de facto unstable self-esteem and fear of experiencing weakness and lack of acceptance. So it may be assumed that their characteristic forms of defence are confrontation, strategies focused on impulsive actions and presented denial of the environment. In the case of extreme self-destruction, the signalised aggression and instability are associated primarily with anxiety, depressed mood and impetuousness. When it comes to interpersonal violence, anger, grief, hostility, somatisation and a tendency to take intoxicants are frequently observed (Çetin, 2001; Kerr et al., 2007; Vermeiren et al., 2003).

In view of the above, the described characteristics of coping are of different importance to the subjects displaying suicidal behaviours and the girls displaying violent behaviours. Therefore, it can be assumed that either what constitutes the mentioned factors is partially different or it is similar but perceived differently and shapes a different kind of structure and mechanisms.

A certain ambiguity of the self-image of the surveyed girls who displayed extreme destructive behaviours draws attention as well. The results obtained in the study could be considered as an 'identity disturbance', since as Meares (2012) suggests there is "a deference between individual's public reality (identity) and private experience (self)".

The negative aspects of self-image of suicide attempters described above are neurotic and depressive. On the other hand, these girls were found to
Self-image and destructive behaviour of adolescent girls 
Katarzyna Sitnik-Warchulska score high in impulsivity, focus on themselves and the need for independence and gratification. This negates passivity and indicates a self-destructive character that is regulative, designed to provide power and importance. Kubacka-Jasiecka's reflections (2006) suggesting that a low level of self-image consistency (high level of discrepancies) triggers fear and de facto restrains aggression seem to be valuable in this regard. Observations indicating that covert dysfunctional narcissism (manifested by withdrawal, a deep sense of lack of understanding, strong criticism and hostility) is related to suicidal tendencies lead to similar conclusions (Aalsma, Lapsley, \& Flannery, 2006; Blasco-Fontecilla, 2009; Arie, Haruvi-Catalan, \& Apter, 2005). Repeated suicide attempts may also be understood as a form of regulation of mood and managing inner distress without involving others, which would suggest limited social support. Chronic environmental invalidation is described as the crucial factor in the development of an unstable self-image (Linehan, 1987a, 1987b, 1989, 1993).

The self-image of the subjects who use interpersonal violence seems equally ambiguous. Conduct disorder is likely to be diagnosed when a person persistently engages in extremely violent behaviours while being aware of their possible effect on herself/himself and others, which suggests some value attributed to one's wellbeing or life and a belief in possessing a certain power or strength. However, the results obtained in the present study indicate that the subjects with violent behaviours have a more adaptable self-image than the subjects with extremely self-destructive behaviours (most of the average results were between the groups SG and CG). Their self-expression in terms of potency coexists with: fear of weakness, disapproval, loneliness, guilt and the need for intimacy that is out of their reach, as revealed in the study. In this context, aggressive behaviours that expose them to constant sanctions may be a mask for a continuous need to fight in order to safeguard their power and importance and, consequently, unstable self-image. These observations are consistent with reports indicating that there is a relation between aggressive behaviour and experienced victimisation (Collin-Vézina et al., 2006) and dysfunctional explicit high-level narcissism based on an early childhood deficiency or dysfunction of the Self in fear of being hurt (Aalsma et al., 2006; Ang \& Yusof, 2005; Lau, Marsee, Kunimatsu, \& Fassnacht, 2011).

Basing the conducted observations on the subjective perception of the surveyed girls might seem limiting to a certain extent. However, different empirical reports indicate that it is only the subjective perception and interpretation of oneself and one's surroundings that play a significant role in the preservation of a specific destructive pattern (Calvete \& Orue, 2011; Çetin, 2001; Kubacka-Jasiecka, 2006; Zhang et al., 2007).

\section{CONCLUSIONS}

The present research supports the belief about the complexity of choices made by contemporary girls. The style and manner in which they manage their developmental issues seem to be directly connected with a desire to shape a self-image that would be distinct but also ensure continuity, which is fundamental in adolescence. Destructive behaviours are generally connected with a negative self-image and low level of its consistency, a low level of self-esteem and a high level of inner conflict. Still, the structure of these factors is related to the direction and kind of destructive activity.

The present research leads to the conclusion that the greatest intensity of difficulties within the self-image is characteristic of self-destructive behaviour. Inner conflict is of particular importance in prediction of suicidal behaviours among adolescent girls. Understanding of these behaviours, especially in the context of the desires of adolescent girls to gain power and importance, may constitute the basis for intervention and therapeutic actions.

The problems with self-image, though not as intense as in the case of self-destructive behaviour, are also characteristic for aggressive behaviour. Of great importance in prediction of violent behaviours among adolescent girls is functioning based on strong desires for power, success and need of orderliness and ability to organise and plan. Understanding of these behaviours in the context of protection against losing power and meaning is important for clinical practice.

At the very end which corresponds to the lowest level of intensity of difficulties within the self-image are girls without destructive behaviour. Their functioning proves to be based mainly on consistency and self-image integration.

Continuation of research involving social or biological risk factors is of great value for a better understanding of destructive behaviours. Moreover, high accuracy of the presented model based on diagnostic tools available to the clinicians and confirmed by discriminant analysis results allows for successful prevention of destructive behaviour in adolescent girls.

\section{REFERENCES}

Aalsma, M., Lapsley, D. K., \& Flannery, D. (2006). Narcissism, personal fables, and adolescent adjustment. Psychology in the Schools, 43, 481-491.

Adrian, M., Miller, A. B., McCauley, E., \& Vander Stoep, A. (2016). Suicidal ideation in early to middle adolescence: sex-specific trajectories and predictors. Journal of Child Psychology and Psychiatry, 57, 645-653.

American Psychiatric Association. (2013). Diagnostic and Statistical Manual of Mental Disorders. American Psychiatry Association. 
Ang, R. P., \& Yusof, N. (2005). The relationship between aggression, narcissism and self-esteem in Asian children and adolescents. Current Psychology, 24, 113-122.

Arie, M., Haruvi-Catalan, L., \& Apter, A. (2005). Personality and suicidal behavior in adolescence. Clinical Neuropsychiatry, 2, 37-47.

Arim, R. G., Dahinten, V. S., Marshall, S. K., \& Shapka, J. D. (2011). An examination of the reciprocal relationships between adolescents' aggressive behaviors and their perceptions of parental nurturance. Journal of Youth and Adolescence, 40, 207-220.

Biel, K. (2009). Przestępczość dziewcząt. Rodzaje i uwarunkowania [Delinquency in girls. Types and conditions]. Kraków: Wydawnictwo WAM.

Blasco-Fontecilla, H., Baca-Garcia, E., Dervic, K., Perez-Rodriguez, M., Lopez-Castroman, J., SaizRuiz, J., \& Oquendo, M. A. (2009). Specific Features of Suicidal Behavior in Patients With Narcissistic Personality Disorder. The Journal of Clinical Psychiatry, 70,1583-1587.

Bleiberg, E. (1994). Borderline disorders in children and adolescents: The concept, the diagnosis, and the controversies. Bulletin of the Menninger Clinic, 58, 169-196.

Brausch, A. M., \& Gutierrez, P. M. (2010). Differences in non-suicidal self-injury and suicide attempts in adolescents. Journal of Youth and Adolescence, 39, 233-242.

Calvete, E., \& Orue, I. (2012). Social information processing as a mediator between cognitive schemas and aggressive behavior in adolescents. Journal of Abnormal Child Psychology, 40, 105-117.

Cash, S. J., \& Bridge, J. A. (2009). Epidemiology of youth suicide and suicidal behavior. Current Opinion in Pediatrics, 21, 613-619.

Collin-Vézina, D., Hébert, M., Manseau, M., Blais, M., \& Fernet, M. (2006). Self-concept and dating violence in 220 adolescent girls in the child protective system. Child Youth Care Forum, 35, 319-326.

Crapanzano, A. M., Frick, P. J., \& Terranova, A. M. (2010). Patterns of physical and relational aggression in a school-based sample of boys and girls. Journal of Abnormal Child Psychology, 38, 433-445.

Currie, C., Zanotti, C., Morgan, A., Currie D., de Looze, M., Roberts, C., Samdal, O., Smith, O. R. F., \& Barnekow, V. (2012). Social determinants of health and well-being among young people. Health behaviour in school-aged children (HBSC) study: international report from the 2009/2010 survey. Copenhagen: Publications WHO.

Çetin, F. Ç. (2001). Suicide attempts and self-image among turkish adolescents. Journal of Youth and Adolescence, 30, 641-651.

Donellan, M. B., Trzesniewski, K. H., Robins, R. W., Moffitt, T. E., \& Caspi, A. (2005). Low self-esteem is related to aggression, antisocial behavior, and delinquency. Psychological Science, 16, 328-335.
Gough, H. G., \& Heilbrun, A. B. (1983). The Adjective Check List Manual. Palo Alto, CA: Consulting Psychologists Press.

Haight, W., Marshall, J., Hans, S., Black, J., \& Sheridan, K. (2010). They mess with me, I mess with them": Understanding physical aggression in rural girls and boys from methamphetamine-involved families. Children and Youth Services Review, 32, 1223-1234.

Herba, C. M., Tranah, T., Rubia, K., \& Yule, W. (2006). Conduct problems in adolescence: three domains of inhibition and effect of gender. Developmental Neuropsychology, 30, 659-695.

Jakab, Z. (2010). Foreword. In D. Sethi, K. Hughes, M. Bellis, F. Mitis, \& F. Racioppi (eds.). European report on preventing violence and knife crime among young people (p. iv). Copenhagen: Publications WHO.

Juros, A., \& Oleś, P. (1993). Struktura czynnikowa i skupieniowa Testu Przymiotnikowego ACL H. G. Gougha i A. B. Heilbruna (Przydatność dla diagnostyki psychologicznej) [The factor and focus structure of the Adjective Check List test by H.G Gough and A.B. Heilbrun]. In J. Brzeziński \& E. Hornowska (eds.), Z psychometrycznych problemów diagnostyki psychologicznej [Psychometric problems in psychological diagnostics] (pp. 171-201). Poznań: Wydawnictwo Naukowe Uniwersytetu im. A. Mickiewicza.

Kerr, D. C., Washburn, J. J., Feingold, A., Kramer, A. C., Ivey, A. Z., \& King, Ch. A. (2007). Sequelae of aggression in acutely suicidal adolescents. Journal of Abnormal Child Psychology, 35, 817-830.

Kubacka-Jasiecka, D. (2006). Agresja i autodestrukcja z perspektyw obronno-adaptacyjnych dążeń Ja [Aggression and Self-destruction in the context of defensive and adaptative self aspirations]. Kraków: Wydawnictwo Uniwersytetu Jagiellońskiego.

Kuhlberg, J. A., Peña, J. B., \& Zayas, L. H. (2010). Familism, parent-adolescent conflict, self-esteem, internalizing behaviors and suicide attempts among adolescent Latinas. Child Psychiatry and Human Development, 41, 425-440.

Lau, K. S. L., Marsee, M. A., Kunimatsu, M. M., \& Fassnacht, G. M. (2011). Examining associations between narcissism, behavior problems, and anxiety in non-referred adolescents. Child and Youth Care Forum, 40, 163-176.

Laukkanen, E., Honkalampi, K., Hintikka, J., Hintikka, U., \& Lehtonen J. (2005). Suicidal ideation among help-seeking adolescents: association with a negative self-image. Archives of Suicide Research, 9, 45-55.

Law, B. M. F., \& Shek, D. T. L. (2016). A 6-year longitudinal study of self-harm and suicidal behaviors among chinese adolescents in Hong Kong. Journal of Pediatric and Adolescent Gynecology, 29(1 Suppl): 38-48.
Self-image and destructive behaviour of adolescent girls 
Linehan, M. M. (1987a). Dialectical Behaviour Therapy: cognitive behavioural approach to parasuicide. Journal of Personality Disorders, 1, 328-333.

Linehan, M. M. (1987b). Dialectical behaviour therapy for borderline personality disorder. Theory and method. Bulletin of the Menninger Clinic, 51, 261-276.

Linehan, M. M. (1989). Cognitive and behavior therapy for borderline personality disorder. In A. Tasman, R. E. Hales, \& A. J. Frances (eds.), Review of Katarzyna Sitnik-Warchulska Psychiatry. Volume 8 (pp. 84-102). Washington, DC: American Psychiatric Press.

Linehan, M. M. (1993). Cognitive-behavioural treatment of borderline personality disorder. New York: Guilford Press.

Makara-Studzińska, M. (2001). Struktura „obrazu własnej osoby” u młodzieży po próbach samobójczych [Structure of the Self-picture of the individual]. Annales Universitatis Mariae Curie-Skłodows ka Lublin- Polonia Sectio D, LV, Suppl. VII, 150-155.

Manseau, H., Fernet, M., Hébert, M., Collin-Vézina, D., \& Blais, M. (2008). Risk factors for dating violence among teenage girls under child protective services. International Journal of Social Welfare, 17, 236-242.

Martowska, K. (2012). Lista Przymiotników ACL. Polska normalizacja [The Adjective Check List ACL. Polish normalization]. Warszawa: Pracownia Testów Psychologicznych Polskiego Towarzystwa Psychologicznego.

Meares, R. (2012). A disassociation model of borderline personality disorder. New York, London: W.W Norton \& Company.

Miller, A., Rathus, J. H., \& Linehan, M. M. (2007). Dialectical behaviour therapy with suicidal adolescents. New York, London: Guilford Press.

Moretti, M. M., Holland, R., \& McKay, S. (2001). Self-other representations and relational and overt aggression in adolescent girls and boys. Behavioral Sciences \& The Law, 19, 109-126.

Nuttin, J. (1968). Struktura osobowości [The structure of personality]. Warszawa: Wydawnictwo Naukowe PWN.

Pajer, K., Leininger, L., \& Gardner, W. (2010). Recognition of facial affect in girls with conduct disorder. Psychiatry Research, 175, 244-251.

Pawłowska, B., Potembska, E., Zygo, M., \& Olajossy, M. (2015). Prevalence of self-injury, suicidal ideation, plans and attempts in adolescents aged 13 to 19 years of age. Polish Journal of Public Health, 125, 55-59.

Pilecka, B. (2005). Osobowościowe korelaty prób samobójczych u mtodzieży [Personality correlates of suicide attempts in adolescents]. Kraków: Wydawnictwo Uniwersytetu Jagiellońskiego.

Rulison, K. L., Gest, S. D., Loken, E., \& Welsh, J. A. (2010). Rejection, feeling bad, and being hurt: using multilevel modeling to clarify the link between peer group aggression and adjustment. Journal of Adolescence, 33, 787-800.

Sacks, J. M., \& Levy, S. (1950). The Sentence Completion Test. In L. E. Abt \& L. Bellak (eds.), Projective psychology: Clinical approaches to the total personality (pp. 357-402). New York: Knopf.

Steele, M. M., \& Doey, T. (2007). Suicidal behaviour in children and adolescents. Part 1: Etiology and risk factors. The Canadian Journal of Psychiatry, 52, 21-33.

Undheim, A. M., \& Sund, A. M. (2010). Prevalence of bullying and aggressive behavior and their relationship to mental health problems among 12- to 15-year-old Norwegian adolescents. European Child and Adolescent Psychiatry, 19, 803-811.

Vermeiren, R., Schwab-Stone, M., Ruchkin, V. V., King, R. A., van Heeringen, C., \& Deboutte, D. (2003). Suicidal behavior and violence in male adolescents: a school-based study. Journal of the American Academy of Child and Adolescent Psychiatry, 42, 41-48.

Vivona, J. M., Ecker, B., Halgin, R. P., Cates, D., Garrison, W. T., \& Friedman, M. (1995). Self- and other-directed aggression in child and adolescent psychiatric inpatients. Journal of the American Academy of Child and Adolescent Psychiatry, 34, 434-444.

Westen, D., \& Chang, Ch. (2000). Personality pathology in adolescence: a review. Adolescent Psychiatry, 25, 61-100.

WHO. (2014). Preventing suicie. A global imperative. Geneva: WHO Report.

Wolińska, J. M., \& Drwal, R. Ł. (1995). Test przymiotnikowy $(\mathrm{ACL})$ H. G. Gougha i A. B. Heilbruna w badaniach samooceny i percepcji społecznej [The Adjective Check List by H.G. Gough and A.B. Heilbrun in study of self-esteem and social perception]. In R. Ł. Drwal, Adaptacja kwestionariuszy osobowości: wybrane zagadnienia i techniki [Adaptation of personality questionnaires: Selected Issues and Techniques] (pp. 67-92). Warszawa: Wydawnictwo Naukowe PWN.

Woźniak, E., Talarowska, M., Orzechowska, A., Florkowski, A., \& Gałecki, P. (2013). The prevalence of suicide attempts among children and adolescents. Polski Merkuriusz Lekarski, 34, 154-157.

Zelkowitz, P., Guzder, J., Paris, J., Feldman, R., Roy, C. \& Schiavetto, A. (2004). Borderline pathology of childhood: implications of early axis II diagnoses. Journal of the Canadian Academy of Child and Adolescent Psychiatry, 13, 58-61.

Zhang, J., Norvilitis, J. M., \& Ingersoll, T. S. (2007). Idiocentrism, allocentrism, psychological well being and suicidal ideation: a cross cultural study. Omega: Journal of Death and Dying, 55, 135-148.

Ybrandt, H. (2008). The relation between self-concept and social functioning in adolescence. Journal of Adolescence, 31, 1-16. 